\title{
Civil Responsibilities of Psychiatrists
}

\author{
Laxmi Narayan Choudhary
}

\begin{abstract}
Legislation is an important part of the life and necessary for social order. Every psychiatrist, in course of his practice, has to deal with various types of legislation or legal issues, which may be either civil or criminal in nature. Forensic psychiatry fills the gap and can be understood as a branch of psychiatry which discusses and deals with these issues originating from interface between law and psychiatric issues. The present article deals with the civil issues which are of concern to the psychiatrist in the course of discharge of his duties. The civil issues which are of importance for psychiatrists are Marriage/Divorce, Competence to be witness, Testamentary capacity, Contract, Adoption, Fitness to take care of person and property, Fitness for job, fitness for work, Voting rights and ineligibility for holding Constitutional posts, Ethical Issues, Civil Liability and liability under the Telemedicine, Telemedicine, and Liabilities under the MHCA 2017. All these issues are discussed in detail.

Keywords: Civil, Legislation, Psychiatry, Telemedicine.

Eastern Journal of Psychiatry (2020): 10.5005/jp-journals-11001-0003
\end{abstract}

\section{INTRODUCTION}

In forensic psychiatry, concept, knowledge, and expertise of psychiatry are used to legal issues in legal contexts of various types of matters including civil, criminal, correctional, or legislative natures. ${ }^{1}$ The subspecialty is not only fast growing but also stimulating and challenging. But unfortunately, still practical skillbuilding aspects of this subspecialty of psychiatry has not been given importance in psychiatry curriculum of either at the UG or at the PG level. With broadening scope of psychiatric services, all psychiatrists are required to have optimum basic skills and knowledge regarding various aspects of forensic psychiatry and to understand the medicolegal aspects of mental health. In addition to the responsibilities to the criminal side of the judicial process, psychiatrists have to discharge various responsibilities in respect of civil issues such as eligibility conditions for marriage, mental Illnesses as a ground for divorce, competency to be witness, testamentary capacity, competency to enter into a contract, and various other spheres of life. All psychiatrists must have a good knowledge, of all these issues, which are discussed in the succeeding paragraphs. It is pertinent to mention here that before a court of law, civil or criminal, the presumption is always in favor of sanity or soundness of mind and if any defence or incapability on account of the mental illness is alleged, the burden of proof falls upon the party who brings the matter unsoundness of mind. It is also pertinent to note that "soundness of mind," "lunacy," "sanity," "idiots," etc. are the terms used in legal parlance and not in the modern psychiatry. These terms are stigmatizing as well. Psychiatrists, when required to submit the reports on psychiatric examination or otherwise, should use the terminology used in modern psychiatry as far as possible together with the terms with which the court are conversant and comfortable. These terms are also used in this article so as to understand the legal provisions without any confusion.

\section{Marriage/DivorCe}

In the chapter titled "the Directive Principle of State Policies" in the Constitution of India which came in force in 1950, it has one of its stated objectives to adopt a Uniform Civil Code. But due to some reasons, it has become a controversial thing. Being a declared
Department of Psychiatry AN Magadh Medical College, Gaya, Bihar, India, L.P. Verma Oration Award, Delivered at Port Blair, CEZIPS 2019, India Corresponding Author: Laxmi Narayan Choudhary, AN Magadh Medical College, Gaya, Bihar, India, L.P.Verma Oration Award, Delivered at Port Blair, CEZIPS 2019, India. Phone: +91 9431223370, e-mail: drclnarayan@gmail.com

How to cite this article: Choudhary LN. Civil Responsibilities of Psychiatrists. East J Psychiatry 2020;23(1):3-7.

Source of support: Nil

Conflict of interest: None

secular state, the law of the lands continues to regard different laws, rules, customs, etc for the different religious group. In 1954, The Special Marriage Act (SMA, 1954) was enacted, which is for any person living in India or any Indian national living outside India, irrespective of their faith. A marriage which has been duly performed in any other form can be registered. Hindu Marriage Act (HMA, 1955) was enacted in 1955 to codify the rules, laws, customs, etc. prevalent in Hindu community. HMA, 1955 is also applicable to a Buddhist, Jain or Sikh, and Buddhist by religion. Anyone who is not Parsi, Christian, Jew, or Muslim can use this Act, unless it is proved that the person would not have been governed by the Hindu law. But as an exception, it is not applicable to members of Scheduled Tribes, unless notified by the Central Government. Regarding the eligibility conditions for solemnization of marriage under the HMA, 1955, following conditions concerning the mental illnesses are mentioned under sec 5 (ii) of the Act.

- "Neither party is incapable of giving a valid consent as a consequence of unsoundness of mind."

- "Even if capable of giving consent, must not suffer from mental disorders of such a kind or to such an extent as to be unfit for marriage and the procreation of children."

- "Must not suffer from recurrent attacks of insanity."

If the marriage is solemnized in contravention of these conditions, it becomes "voidable" in legal perspective. ${ }^{2}$

The grounds on the basis of mental illness for judicial separation and divorce is when the other party is:

(c) The Author(s). 2020 Open Access This article is distributed under the terms of the Creative Commons Attribution 4.0 International License (https://creativecommons. org/licenses/by-nc/4.0/), which permits unrestricted use, distribution, and non-commercial reproduction in any medium, provided you give appropriate credit to the original author(s) and the source, provide a link to the Creative Commons license, and indicate if changes were made. The Creative Commons Public Domain Dedication waiver (http://creativecommons.org/publicdomain/zero/1.0/) applies to the data made available in this article, unless otherwise stated. 
- "incurably of unsound mind,"

- "or has been suffering continuously or intermittently from mental disorder of such a kind and to such an extent that the petitioner cannot reasonably be expected to live with the respondent."

"Mental disorder" has been defined in the Act, and it is described in various forms. These can be a mental illness, an arrest, or incomplete development of mind. Other descriptions are of a psychopathic disorder or of any other disorder or disability of mind including schizophrenia. "Psychopathic disorder" has also been defined and described as a continuing disorder or disability of the mind. This may or may not include subnormality of intelligence but leads to excessively aggressive or gravely irresponsible conduct on the part of the other party, and regardless of requiring and susceptible to medical treatment.

The grounds of ineligibility for marriage and grounds for divorce/judicial separation under the Special Marriage Act, 1955 are similar to the HMA, $1955 .^{3}$

Divorce/Judicial separation on the above grounds is granted only after the above conditions are established and the responsibility of proving is on the party seeking divorce on this basis. The Supreme Court of India has elaborated further upon the matter and clarified the things. For example, each case of schizophrenia must be looked into on its own merits. The medical evidence related to the mental disorder is pertinent, but it cannot be made conclusive [Sharada vs Dharmapaul (2003, 4 SCC 493)]. To say that the wife as unfit for marriage and procreation of children due to mental disorder, it must be established that the illness is of such a kind or extent that leading a normal married life is impossible for her (R. Lakshmi Narayan vs Santhi, AIR 2001 SC 21 10). In an earlier case, where the court could not find sufficient evidence to conclude that the mental disorder of the wife was of such a kind or extent that it could not expected that the husband could live with her, divorce was not granted (A.I.R., 1982 CAL 138). The court also cautioned that the meaning of "incurably" should not be interpreted in such a way that the feeble minded persons or persons of dull intellect who can understand the nature and consequences of the act and are therefore able to control them and their affairs, and their reaction in the normal way get covered with its meaning (A.I.R. 1969 Guj-48 and 78 CLT [1994] 561). ${ }^{4}$

Marriage is a type of contract under the prevalent Muslim Law. Whenever a Muslim attains puberty and if he is of sound mind, he is qualified to marry. In Muslim Law, matter of unsound mind is looked into in a different way. If the guardian of the person thinks that such a marriage will be of interest of the person and of the society and if the guardian is willing to take up all the monetary obligations of the marriage, then such a marriage can be performed. Under Muslim Law, Talaq (Divorce) must be for a reasonable cause and has to be preceded by attempts for reconciliation by two arbiters. Triple Talaq at one go has been banned and made punishable by Law recently. According to a woman married under Muslim Law can obtain a decree of divorce if her husband has been insane for a period of 2 years (Muslim Marriage Act, 1939).

Under Christian Law, under different conditions, marriage becomes voidable. If either party was a lunatic or idiot at the time of marriage, then marriage is voidable. Under Indian Divorce Act 1869 (as amended in 2001), on grounds of unsoundness of mind if it is incurable and present for at least 2 years immediately preceding the petition, a Christian can obtain divorce.

Solemnization by Ashirvad ceremony is a prerequisite for validity of marriage under Parsi Marriage and Divorce Act, 1936.
Under this Act neither unsoundness of mind is not a ground for voiding of marriage nor divorce is admissible for mental illness. However, divorce can be obtained under two conditions. One is if the defendant was found to be of unsound mind at the time of marriage and provided the plaintiff was ignorant. Other condition is if the defendant has been found of unsound mind for 2 years upwards and immediately preceding the application. ${ }^{2}$

\section{Competency to be a Witness}

According to the section 118 of Indian Evidence Act, 1872, any person is competent to testify as a witness provided fulfilling following conditions. One is that he must understand the obligation of oath. Other is that he must understand the nature of questions put to him. Thus, an insane person is not necessarily incompetent to be a witness. He is incompetent to be witness only if he is not able to understand the questions or is unable to give rational answers to them. If an insane person can describe the facts seen by him and provided, he does not make interpretations, this can be accepted by the Court. What is called to be lucid interval in the legal parlance is an exception in this respect and his competency for witness during this period is accepted by the Court. The competency for the purpose of testifying as a witness must be decided by the presiding officer of the Court. The presiding officer may, at its discretion, solicit an expert opinion from a psychiatrist for the purpose, who may submit his report after examining the person.

\section{Testamentary Capacity}

Psychiatrists may be required to assess the testamentary capacity of a person. Testamentary capacity is the legal capacity to execute a Will. All adults are presumed to possess the testamentary capacity unless established otherwise. Section 59 of Indian Succession Act 1925 says that any person can make a will if he is having sound mind and has reached the age of majority. A married woman may make a Will of her property which she could alienate by her own act during her life-time. For ordinarily insane persons, they can make a Will during the period when they are of sound mind. Few specific prerequisites are necessary for testamentary capacity. Executing a Will is a voluntary act on the part of the testator and at the time of executing the Will. ${ }^{5} \mathrm{He} /$ she must:

- Have a sound disposing mind and free from delusions that influence disposition of the assets.

- Understand what he is doing by making a Will.

- Have sufficient capacity to the extent that he knows the extent of his property.

- Be aware of potential and reasonable beneficiaries of his Will.

- Be aware of the consequences of his/her decision.

- Be free from undue influence/fraud/coercion from any person.

- Must know and fully understand the contents of the Will.

\section{Contract and Transfer of Property}

The related act is called the Indian Contract Act, 1872, which has laid down definition of Contract. It is an agreement enforceable by Law. For making a Contract, a person formulates a proposal which is then communicated to the other party. The other party may either accept the proposal or proposes certain modification in the proposal. After negotiations, a final mutually acceptable proposal is drafted and accepted by the parties. The Contract is said to be complete when the proposal is accepted by both the parties and 
the acceptance is conveyed to each other. The parties executing the Contract must fully understand all the aspects and repercussions of the contract. Naturally, it requires a state of mind which is free from any disorder which renders the person incapable to doing so. The sections in the Indian Contract Act, which are relevant in this respect are as follows.

- Section 6: Revoking of a proposal occurs when there is death or insanity of the proposer when the acceptor gets to know before acceptance.

- Section 11: Above the age of majority a person is competent to contract.

- Section 12: Says that a person is said to be of sound mind if it is found that at the time of making the contract, he/she understands it and can form a rational judgment as to its effects.

A person, who is usually of unsound mind, but occasionally of sound mind, may make a contract when he is of sound mind. A person, who is usually of sound mind, but occasionally of unsound mind, may not make a contract when he is of unsound mind. It means a person with mental illness (PMI) who is currently free of the psychotic symptoms can make a contract, whereas a person who is currently intoxicated or delirious cannot make a contract.

Transfer of property is also regarded as act of Contract in which a property or asset, movable or immovable, is transferred to another person for a consideration. The transfer of property is governed by the Transfer of Property Act, 1882. According to Section 7 of this Act, which says that "every person competent to contract and entitled to transferable property or authorized to dispose of transferable property not his own, is competent to transfer such property either wholly or in part, and either absolutely or conditionally, in the circumstances, to the extent and in the manner, allowed and prescribed by any law for the time being in force."

\section{Adoption}

The related act is Hindu Adoption and Maintenance Act (Act 78 of 1956). Under this act, any Hindu male "who is of sound mind and is not a minor" can adopt a child. The additional essential requirement is consent of his wife. This must be supplemented by the fact that the wife is not declared to be of unsound mind (Section 7). The some holds good for female also. Also, the person who can give in adoption should also be of sound mind.

\section{Fitness to Take Care of a Person and Property}

The provision of Judicial Inquisition as contained in the chapter VI of the Mental Health Act, 1987 (MHA- 1987) has been dropped in the newly enacted Mental Healthcare Act, 2017 (MHCA). ${ }^{6}$ Now, management of property of the PMI is governed by the Section 14 of the Rights of Persons with Disabilities Act 2016 (RPWD Act, 2016). Sec 14 of the Act says about "Limited guardianship." A State Government-notified district court or any designated authority, finds that if a person with disability had been provided support but he/she is unable to take legally binding decisions, he/she may be provided further support by means of a limited guardian. A limited guardian must take legally binding decisions on behalf of the person of whom he/she is a limited guardian of, in consultation with such person. It is a system of joint decision which operates on mutual understanding and trust between the guardian and the person with disability. This is limited to a specific period and for specific decision and situation. The limited guardianship works in accordance with the will of the person with disability. The District Court or the designated authority may modify this like providing total support or granting guardianship repeatedly upon review by the Court or designated authority. These cases shall be reviewed by the Court or the designated authority. Every such person who are appointed guardian shall be considered to function as a limited guardian after promulgation of the Rights of Persons with Disability Act. ${ }^{7}$

\section{Fitness for Job, Fitness for Work}

Fitness certificate should generally be not issued in cases of psychiatric disorders unless asked by the employer in writing. Proper clinical examination, observation, and psychological evaluation are necessary for issue of the fitness certificate. If necessary, the psychiatrist may get the patient admitted for observation for a period of 10 days for the purpose before issuing the certificate. It is advisable that a Medical Board is constituted while assessing the fitness in cases of psychiatric disorders. Nature of the job is to be kept in mind during the process of evaluation for the fitness certificate. Certificate of leave from work is to issued according to the process recommended by the $\mathrm{MCl}$ for physical illness. Period of leave should be short, e.g., for weeks rather than for months. Re-certification of leave should be done after proper assessment. There is no upper limit for the leave. After the person has recovered from the illness, the psychiatrist should issue the fitness certificate. But here again the nature of the job has to be kept in mind and caution may be required in some cases, e.g., paranoid schizophrenia. Constitution of a medical board may be required in some cases.

\section{Voting Rights and Ineligibility for Holding Constitutional Posts}

The Representation of People Act, 1950 (Sec 16) says that if a person is of unsound mind and stands so declared by a competent court, he/she is disqualified for registration in an electoral roll. Thus, if a person is disqualified by such, he/she cannot hold public offices under the Constitution like President, Vice-President, Ministers, or Member of Parliament and State Legislatures, etc. ${ }^{8}$

\section{Ethical Issues}

Ethics represents a system of internal controls by moral principles and is largely unwritten, whereas Law represents a mechanism for external controls and is purposefully written and enforceable by the state. ${ }^{9}$ Frequently, the professional associations/bodies issue ethical guidelines which is to be followed by their members. Respect of autonomy, beneficence, nonmaleficence, justice, and confidentiality. Informed consent, honesty and striving for objectivity, and taking care of boundary violation are example of the ethical issues. Though ethical issues are not enforceable in a court of Law, but the matter of nonadherence to the ethical guidelines may be brought into the picture in cases in which the professional conduct of the medical professional is under scrutiny. Violation of the ethical guidelines issued by a professional body or a statutory body may attract punitive action by the body issuing the guidelines. For instance, the Medical Council of India has a guideline meant for doctors registered with it, and it has to be adhered to by all the doctors. If any instance of violation of the code of ethics is brought before it in a complaint, the Council may take various 
type of punitive action after the violation is established. Some of the ethical issues has also found places in enacted legislation. For example, the matter of informed consent now finds its place in the MHCA, 2017 and various issues pertaining to the human rights have been incorporated in the Rights of Peoples with Disability Act, 2016. Some of the ethical issues, like confidentiality, are regarded as legal obligation and suit may be brought against the professional for its violation. Psychiatrist has to maintain confidentiality regarding the identity of the patients or the matters communicated to him during the process of consultation. This information cannot be divulged only in very exceptional and specific situations.

\section{Civil Liability and Liability under CPA, 2019}

Medical professionals may be sued in a court of Law on account of medical negligence which is breach of a legal duty to care. Every doctor has a duty to act with a reasonable degree of care and skill, which is neither very high standard of care nor very low degree of care. If the medical professional has acted in accordance to a practice accepted as proper by a responsible body of medical men skilled in that particular art, he is said not to have committed the medical negligence (Bolam Test). The medical professional may follow a Clinical Practice Guidelines set by a responsible professional association. Failure to use such care as a reasonably prudent and careful person would use under similar circumstances would also amount to medical negligence. The person who brings a case of medical negligence has three options to act against the medical professionals:

- File a case of civil wrong or tort in a court of law dealing with civil cases.

- File a complaint against the doctor in a consumer protection forum under the Consumer Protection Act. This is a simple, easy and quick way of grievance redressal. Therefore, it is the popular way of filing complaints against a medical professional.

- File a complaint to the concerned Medical Council. The Medical Council may take various type of actions against the doctors upon complain after doing proper investigation.

In the recently enacted Consumers Protection Act 2019, "Service" has been described. It means service of any nature or description. This is made available to potential users. This may include but not limited to, the provision of facilities related to diverse sectors ranging from banking, financing to entertainment, etc. This excludes rendering of any service which is free of charge or is under a contract of personal service. ${ }^{10}$ Medical service being a contract of personal service may be considered to be excluded from its purview. But it is to be seen what interpretation is applied to this definition by the judiciary.

If the medical professional is accused of gross a reckless negligence, a case of criminal negligence may be instituted against him under section 304 (A). But the negligence to be established under this charge must be gross, reckless, and culpable and not merely based upon an error of judgment. Burden of proof lies upon the prosecution and the charge has to be established beyond doubt before the medical officer is convicted under this section. Criminal liability would arise only if the doctor did something in disregard of the life and safety of the patient, which went beyond a mere question of compensation on the basis of civil liability. (Jacob Matthew vs State of Punjab and another, 2005 SCCL COM 456). The Supreme Court has also issued a detailed guideline for instituting a case and acting against the doctor under section 304(A) in the same case.

\section{Informed Consent}

Consent is closely related to the concept of rights of autonomy. The patient who has come to seek consultation has certain rights related to information of his treatment. Before according his/her consent, the patient takes all the relevant information into account. The information must be provided to him/her in a way leading to meaningful decision-making. A person with mental illness, on some occasions, may lack the capacity to make treatment decision. After obtaining consent from their suitable person/relatives/caregiver as per legal provisions, treatment decisions and details should be considered with utmost care for them. MHCA 2017 has defined informed consent as follows "It is the consent given to a proposed specific intervention, without any force, undue influence, fraud, threat, mistake, or misrepresentation, and obtained after disclosing to the person adequate information including risks and benefits of, and alternatives to, the proposed intervention in a language and manner understood by the person." The MHCA, 2017, also defines as "the capacity to make mental health care and treatment decisions" and says that a person with mental illness shall be considered to have capacity for making decisions regarding his treatment decision under the following:

- If he/she has ability to understand the information relevant to treatment decision;

- If he/she has ability to retain that information;

- If he/she is able to use or e.g., that information as a part of the process of making the mental health care or treatment decisions; and

- If he/she can communicate his decision by any means (including talking, using sign language or any other means). ${ }^{6}$

If the person lacks this capacity, the treating psychiatrist has to take informed consent from the nominated representative of the PMI. Regarding psychosurgery, both informed consent of the person concerned and approval of the Mental Health Review Board (MHRB) should be taken by treating psychiatrist. Free and informed consent is required for any research to be performed on the PMI. If the person is not able to accord his consent, permission is required from the State Mental Health Authority which can grant to permission only when it is in the interest of the PMI and also necessary for promotion of mental health. But if anonymity is maintained, research-based case study may be performed.

\section{Telemedicine}

With the advancement in electronic channels of communications, Telemedicine is a newly emerging phenomena and psychiatrists have to remain aware of this. The Board of Governor governing the Medical Council of India has recently issued a guideline for Telemedicine in India. In the guideline, Telemedicine is defined as "the delivery of health care services, where distance is a critical factor, by all healthcare professionals using information and communication technologies for the exchange of valid information for diagnosis, treatment and prevention of disease and injuries, research and evaluation, and for the continuing education of health care providers, all in the interests of advancing the health of individuals and their communities."11 For a country like India with a large population living in remote places, Telemedicine may be of great advantage and cost saving especially for the rural 
patients as they need to travel for long distance. Often disasters and pandemics across the globe throw unique challenges to health care delivery systems. Telemedicine may be especially useful in such situation. Telemedicine may also be useful in situations in which a doctor may discuss the case and seek guidance from a specialist or a healthcare worker may seek guidance from a doctor. In Telemedicine, the physician is not conducting a direct examination of the patient and not able to deliver a signed prescription. Consent from the patient side is to be communicated through the channel used for delivering the Telemedicine healthcare. Telemedicine is permissible with some limitation in first consultation and in subsequent consultations. In established doctor-patient relationship, Telemedicine consultation has been made permissible in certain circumstances. A Mumbai High Court decision in 2018 (Pawaskar vs State of Maharashtra) passed certain observation against the Telephonic consultation. But in that case, several other issues were also involved and the Court did not make any specific observation against the practice of Telemedicine. After issuance of the guideline by the Medical Council, all doctors are to be guided by this guideline only and the practice would be regarded as legal, if it is performed within the framework as given in the guideline. Different rules are provided for the first consultation as well as the subsequent consultations. Any consultation after 6 months is regarded as a fresh consultation. The guideline gives four groups of drugs which may be advised to the patient by Telemedicine mode as per the guidelines. The guidelines do not allow prescribing the schedule $X$ drugs, which are controlled by Narcotics and Psychotropic Substances Act (NDPS Act). ${ }^{10}$ But the drugs such as clonazepam, phenobarbitone and clobazam can be prescribed via Telemedicine mode.

\section{Liabilities Under the MHCA 2017}

The MHCA was promulgated in $2017 .{ }^{6}$ It has imposed new responsibilities upon the psychiatrists. At the district level, an MHRB is to be formed to discharge many functions as assigned in the Act. Psychiatrists has to take care of advance directive. If the person lacks the capacity to take mental healthcare decision, the psychiatrist has to find out if there is any advance directive executed by the person. Any person, not a minor, has right to make and have an advance directive. Online register of the advance directives has to be maintained by the MHRB. If there is any such directive, it has to be followed except in certain exceptional circumstance. Similarly, every person, not a minor, has a right to designate a nominated representative. As mentioned above, the psychiatrist has to take consent from the nominated representative of the person, if he lacks the capacity to take mental healthcare decision. The Act describes in detail provisions about all types of admission and discharge, like voluntary admission, admission of minors, supported admissions, and emergency admissions. The MHCA 2017 has prohibited electroconvulsive therapy (ECT) without anesthesia and only after approval of MHRB, ECT can be administered to minors. Restraint and seclusion can be given in exceptional circumstances and after the documented approval by the treating psychiatrist.

\section{Conclusion}

Being aware of the laws of the State and having a better understanding of the medicolegal aspects of psychiatry and mental health is an important aspect for a psychiatrist in recent times. Increasing awareness of rights of patients may result in an increase in litigation. Also, several civil rights movements and consumer protection forums are gaining tractions in our day-to-day life. All information is now available at fingertips to practically everyone after increasing access to the Internet. In this scenario it has become all the more important for all psychiatrist to be aware of their legal responsibilities.

\section{References}

1. Nambi S, Ilango S, Prabha L. Forensic psychiatry in India: past, present and future, Indian J Psychiatry. 2016; 58(Suppl 2): S175-80.

2. Rao TS, Nambi S, Chandrashekhar H. Marriage, mental health and the Indian legislation. Clinical Practice Guidelines on Forensic Psychiatry: Indian Psychiatric Society; 2009. pp. 113-128.

3. Narayan $C L$, Narayan $M$, Shikha $D$, et al. Indian marriage laws and mental disorders: is it necessary to amend the legal provisions? Indian J Psychiatry 2015;57:341-344. DOI: 10.4103/0019-5545.171836

4. Narayan CL, Narayan $M$, Shikha D, et al. Perspectives on marriage and mental health. Bengal J Psychiatry 2015;6(2\&3): 50-57.

5. Jiloha, RC. Mental Capacity/Testamentary Capacity Clinical Practice Guidelines on Forensic Psychiatry: Indian Psychiatric Society; 2009. pp.20-34.

6. The Mental Healthcare Act, 2017. Available at https://www.prsindia. org/ (last accessed on 11-04-2020).

7. Narayan CL, John T. The rights of persons with disabilities Act, 2016: does it address the needs of the persons with mental illness. Indian J Psychiatry 2017;59(1):17-20. DOI: 10.4103/psychiatry. IndianJPsychiatry_75_17

8. Narayan CL, Shikha D. Indian legal system and mental health. Indian J Psychiatry 2013;55:177-181. DOI: 10.4103/0019-5545.105521

9. Singh, PK. Ethics and law. In clinical practice guidelines on forensic psychiatry: Indian Psychiatric Soc; 2009, pp.141-147.

10. Consumer Protection Act, 2019. Available at https://consumeraffairs. nic.in/sites/default/files/CP\%20Act\%202019.pdf (last accessed on 11-04-2020).

11. Telemedicine Practice Guidelines. Available at https://www.mohfw. gov.in/pdf/Telemedicine.pdf (last accessed on 11-04-2020). 